\title{
Laparoscopic intra-peritoneal onlay mesh plus repair for ventral abdominal wall hernias - is there substance to the hype?
}

\author{
Kalpesh Jani \\ Vadodara Institute of Gastrointestinal and Obesity Surgery, Manjalpur Hospital, Vadodara 390011, India. \\ Correspondence to: Dr. Kalpesh Jani, Vadodara Institute of Gastrointestinal and Obesity Surgery, Manjalpur Hospital, Tulsidham \\ Cross Roads, Manjalpur, Vadodara 390011, India. E-mail: kvjani@gmail.com

\begin{abstract}
How to cite this article: Jani K. Laparoscopic intra-peritoneal onlay mesh plus repair for ventral abdominal wall hernias - is there
\end{abstract} \\ substance to the hype? Mini-invasive Surg 2018;2:14. http://dx.doi.org/10.20517/2574-1225.2018.08 \\ Received: 6 Feb 2018 First Decision: 16 Apr 2018 Revised: 24 Apr 2018 Accepted: 3 May 2018 Published: 28 May 2018 \\ Science Editors: Charles F. Bellows, David S. Edelman Copy Editor: Jun-Yao Li Production Editor: Cai-Hong Wang
}

\begin{abstract}
Aim: To summarize our experience in laparoscopic intra-peritoneal onlay mesh (IPOM) plus repair for ventral abdominal wall hernias over a 10 -year period.

Methods: All patients posted for laparoscopic repair of midline lower abdominal ventral hernia on an intention to treat basis were included in the study. Patients unfit for general anesthesia, patients posted for open repair or a hybrid approach (open reduction and closure of defect followed by laparoscopic IPOM repair) were excluded. Pre-operative patient demographics were noted. Intra-operative and post-operative data was recorded and analyzed.
\end{abstract}

Results: A total of 278 patients were posted for elective laparoscopic repair of lower midline ventral hernias between January 2007 and January 2017, of which, 56.1\% were para-umbilical hernias and 43.9\% were incisional hernias. These included 155 female patients. The average body mass index was $27 \mathrm{~kg} / \mathrm{m}^{2}$. Thirty-five patients were being operated for a recurrent ventral hernia. The average defect width was $1.2 \mathrm{~cm}$ for paraumbilical hernias and $2.2 \mathrm{~cm}$ for incisional hernias. The mean operating time was $55 \mathrm{~min}$ for para-umbilical hernias and $71 \mathrm{~min}$ for incisional hernias. In 13.1\%, the fascia could not be sutured. There were no conversions to open surgery. Average length of hospital stay was 2.04 days with average follow-up period of 4.6 years. Overall morbidity was $7.9 \%$ with 2 recurrences. There was no mortality or mesh infection.

Conclusion: Thus, IPOM plus repair is a safe, feasible and effective technique for the treatment of ventral abdominal wall hernias.

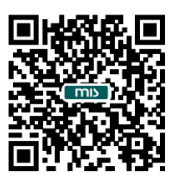


Keywords: Laparoscopic ventral hernia repair, intra-peritoneal onlay mesh plus repair, closure of defect in the fascia, abdominal wall hernia, incisional hernia repair, para-umbilical hernia repair

\section{INTRODUCTION}

Ventral abdominal wall hernia surgery is a common procedure in the armamentarium of surgeons. The commonest forms of these surgical procedures in adults are repair of incisional hernias and surgery for paraumbilical hernia. Incisional hernias after previous abdominal surgeries occur in a varying range, reported from $11 \%$ to $20 \%{ }^{[1-3]}$. Laparoscopic repair of such hernias has an advantage of shorter hospital stay, lower wound infection, earlier recovery and recurrence rates less than $5 \%^{[4-6]}$. Paraumbilical hernias compromise $10 \%-12 \%$ of abdominal wall hernias ${ }^{[7]}$. As compared to open repair, laparoscopic repair of adult paraumbilical hernias has also shown favorable outcomes ${ }^{[8]}$. Since its first description in 1993, laparoscopic repair of ventral hernias is gaining acceptance and becoming more popular by the day worldwide ${ }^{[9]}$. However, the standard laparoscopic repair of ventral hernias consisted of bridging the defect from the peritoneal side with a composite mesh, known as the intra-peritoneal onlay mesh (IPOM) repair, which is placement of the mesh in the underlay position through the laparoscopic intraperitoneal approach. Such repair is associated with a significant incidence of post-operative bulging or eventration of mesh, seromas, recurrences and nonrestoration of abdominal muscle function ${ }^{[10-12]}$. To circumvent these problems, sutured closure of the defect in the fascia with intra-peritoneal mesh reinforcement has been described, termed the IPOM plus repair ${ }^{[13]}$. This repair is now the recommended procedure in the guideline of International Endohernia Society ${ }^{[14]}$.

In this paper, we summarize our experience of the IPOM plus repair over a period of 10 years, beginning from January 2007 to January 2017.

\section{METHODS}

All patients posted for laparoscopic repair of midline lower abdominal ventral hernia on an intention to treat basis were included in the study. Patients unfit for general anesthesia, patients posted for open repair or a hybrid approach (open reduction and closure of defect followed by laparoscopic IPOM repair) were excluded. This approach removed patients with incarcerated, obstructed or strangulated hernias from this study as these patients were managed either by open repair or a hybrid approach. This also excluded patients with domain loss (width of the gap in fascia in resting supine position) of more than $8 \mathrm{~cm}$. as these patients were electively posted for open repair prior to 2015 or given a choice of open/laparoscopic component separation reconstruction of abdominal wall after 2015.

The width of the defect was measured as the maximum distance between the medial edges of the defect in the fascia when the patient is in a resting supine position. The average defect width was $1.2 \mathrm{~cm}$ (range: $0.8-2.4 \mathrm{~cm}, \mathrm{SD}$ $0.29 \mathrm{~cm}$ ) for paraumbilical hernias and $2.2 \mathrm{~cm}$ (range: 1.0-7.5 cm, SD $0.49 \mathrm{~cm}$ ) for incisional hernias.

The operating time was calculated from the insertion of the first trocar to exsufflation. The technical details of the surgery are briefly described. The patient was placed supine with both upper limbs by the side. The monitor was at the foot end of the operation table. The surgeon stands near the head of the patient with the camera surgeon to his left.

Ryle's tube is inserted to ensure a deflated stomach. Pneumoperitoneum is achieved by insufflating through a Veress needle inserted either below the xiphisternum, slightly to the left of the midline or at Palmer's point. Three ports are inserted [Figure 1]. Port A is optional, required only if there is adhesiolysis to be done. In such a situation, port $\mathrm{B}$ serves as the camera port, while port $\mathrm{A}$ and $\mathrm{C}$ are the right and left hand working ports. For suturing the defect and mesh placement, port $\mathrm{C}$ is the camera port while port $\mathrm{B}$ and $\mathrm{D}$ are the working ports. 


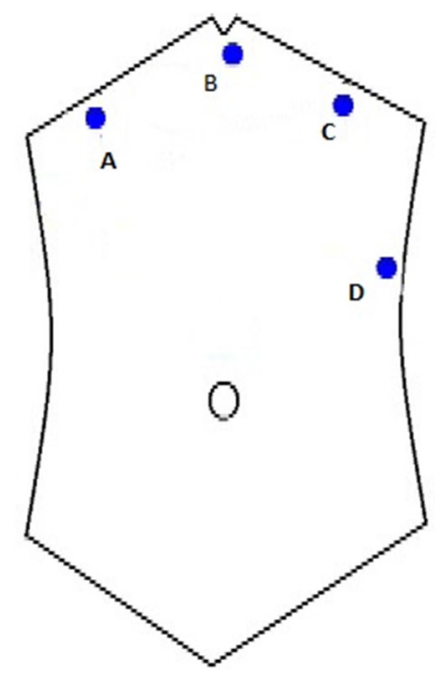

Figure 1. Port positions

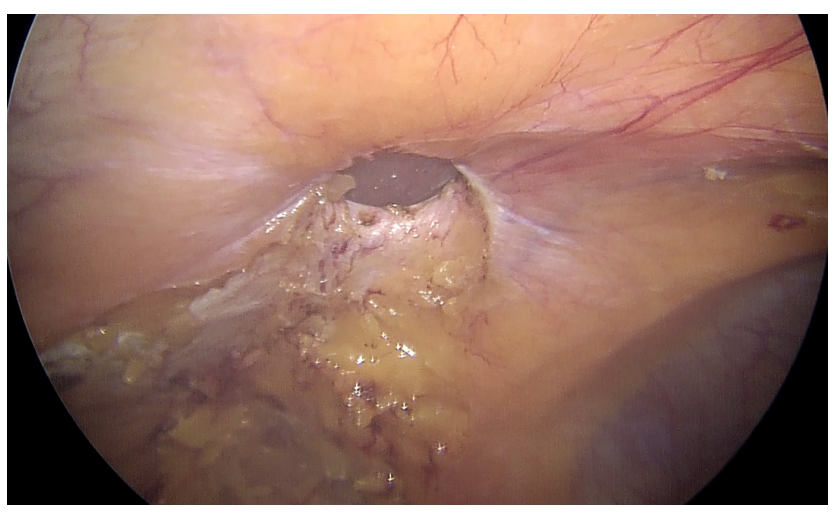

Figure 2. Para-umbilical hernia after adhesiolysis

After adhesiolysis, the hernia sac is excised [Figure 2]. The defect is closed intra-corporeally with continuous sutures, using polyamide no 1 suture for para-umbilical hernia and polyamide no 1 loop for incisional hernias. The intra-peritoneal pressure may be reduced at this time to $8-10 \mathrm{~mm}$ of mercury to facilitate this step [Figures 3 and 4]. Composite mesh (Parietex Optimized Composite Mesh, Medtronic, USA) is introduced for intra-peritoneal placement of a size sufficient to ensure a minimum of $5 \mathrm{~cm}$ overlap of the edges of the defect. The mesh is first oriented with 5 transfascial sutures - 1 central and 4 peripheral, with the central sutures passed through the center of the defect to ensure proper alignment. Up to 2010, the 4 peripheral sutures were placed at the 4 corner of the mesh. However, we discovered that better alignment was obtained by placing the 4 peripheral sutures in a cross shaped pattern, along the vertical and horizontal axes of the mesh and have been doing so since then. Thereafter, interrupted intracorporeal sutures are placed at a distance of 1-1.5 cm with polyester 2-0 to complete the mesh fixation [Figure 5]. Hemostasis is ensured before desufflation.

The Ryle's tube is removed before extubation of the patient. The patients are mobilized and liquids orally are allowed once they are fully awake and non-sedated, usually 3-4 h after the surgery.

If multiple Swiss cheese types of defects are there in the fascia or the fascia is very thinned out and the fascial closure sutures tend to cut through, an IPOM repair is done. Patients are discharged after 24-48 h once they are fully mobile and comfortable on oral analgesics. 


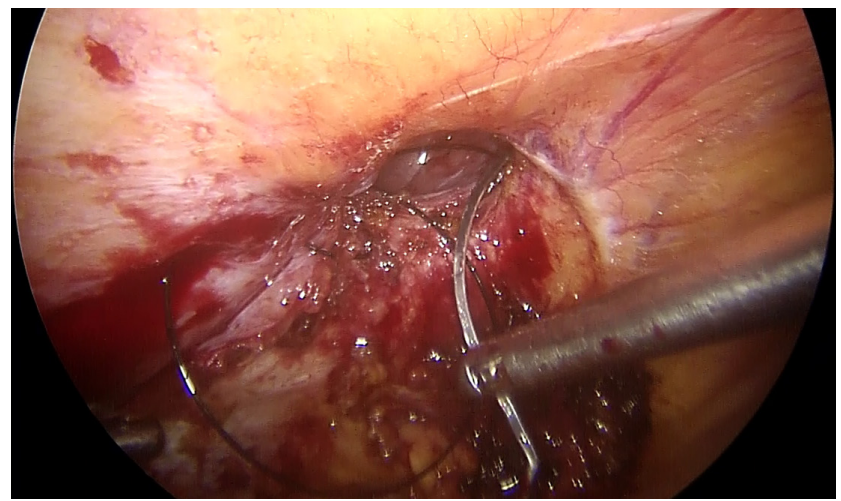

Figure 3. Intra-corporeal suturing of the fascial defect

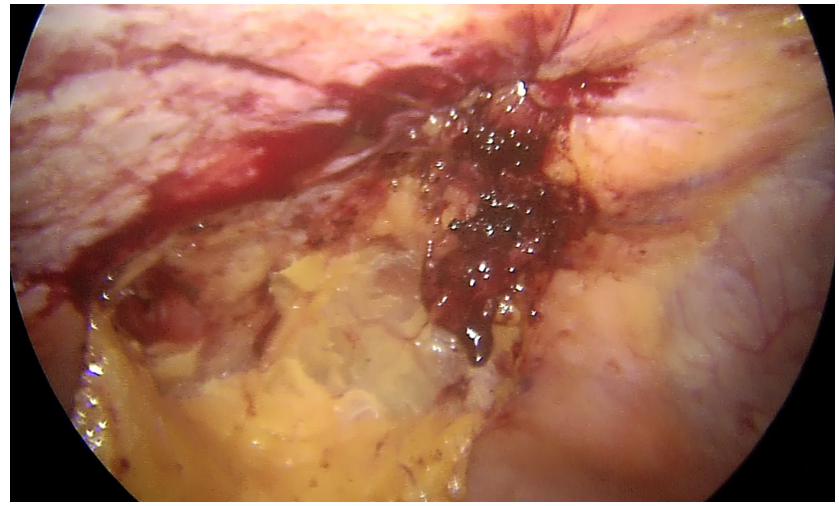

Figure 4. After closure of the fascial defect

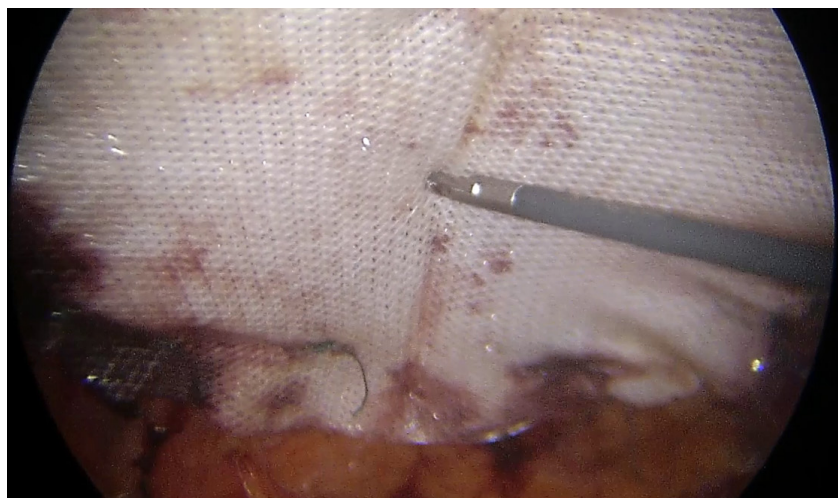

Figure 5. Intra-peritoneal onlay mesh placement and fixation

Patients are called for routine follow-up after 7 days, 1 month, 3 months, 6 months, 1 year and yearly thereafter. If patients do not physically attend their follow-up date, attempt is made to contact them telephonically. During follow-up visits, patients' complaints, if any, are noted and physical examination is done. Any suspicious bulge at the site of the previous lesion is investigated with an ultrasonography scan.

Chronic pain was defined as pain persisting at operative site beyond 6 months for which the patient needs to consume analgesic for relief. 
Table 1. Patient demographics

\begin{tabular}{ll}
\hline Demographics & \multicolumn{1}{c}{ Data } \\
\hline Total number of patients in the series $(n)$ & 278 \\
Male:female & $123: 155$ \\
Body mass index $\left(\mathrm{kg} / \mathrm{m}^{2}\right)$ & $27($ range: $21-41)$ \\
Diabetes mellitus, $n(\%)$ & $58(20.9 \%)$ \\
Smoker, $n(\%)$ & $17(6.1 \%)$ \\
COPD,$n(\%)$ & $26(9.4 \%)$ \\
Mean ASA score & $2.2($ range: $1-4)$ \\
\hline
\end{tabular}

COPD: chronic obstructive pulmonary disease; ASA: American Society of Anesthesiologists

Table 2. Operative and immediate post-operative findings

\begin{tabular}{ll}
\hline Characteristics & \multicolumn{1}{c}{ Data } \\
\hline Operating time (min) & 55 (range: 36-68) \\
$\quad$ Para-umbilical hernia & 71 (range: 55-105) \\
$\quad$ Incisional hernia & Nil \\
Conversion to open & $5(1.8 \%)$ \\
Intra-operative bowel injury, $n(\%)$ & $16 / 122(13.1 \%)$ \\
Inability to suture the defect due to thinned out fascia & \\
(IPOM repair only) (incisional hernias), $n(\%)$ & 2.04 (range: $1-5)$ \\
Length of stay (days) & \\
\hline
\end{tabular}

IPOM: intra-peritoneal onlay mesh

\section{RESULTS}

Between January 2007 and January 2017, a total of 278 patients were posted for elective laparoscopic repair of lower midline ventral hernias which, $156(56.12 \%)$ were para-umbilical hernias and $122(43.88 \%)$ were incisional hernias. Majority of incisional hernias $(n=94,77.1 \%)$ were in women following either a lower segment caesarean section or hysterectomy or surgery for other gynecological pathology. In case of former two instances, though the scar on skin was Pffanensteil, the defect in the fascia was oriented in the midline vertical craniocaudal plane. Males outnumbered females in the group with para-umbilical hernias $(n=105$, 67.3\%). The patient demographics are summed up in Table 1.

A total of 35 patients had undergone prior hernia repair, of which 11 para-umbilical hernias had all suffered a failed open repair. Of these, 8 were anatomical repairs while 3 were mesh repairs. Of the 24 incisional hernias which were recurrent, 20 had undergone previous open repair while 4 had undergone laparoscopic repair. Eighteen of the open repairs and all 4 of the laparoscopic repairs had received polypropylene mesh augmentation as part of their primary repair. The width of the defect is reported separately for para-umbilical hernias and incisional hernias. In case of para-umbilical hernias, the defect ranged 1-2.5 cm, with an average of $1.2 \mathrm{~cm}$. For incisional hernias, the defect width ranged $1-8 \mathrm{~cm}$, with an average of $2.2 \mathrm{~cm}(\mathrm{SD} 0.74 \mathrm{~cm})$. The operative and immediate post-operative findings are summarized in Table 2.

Diligent follow-up was maintained with an average follow-up of 4.6 years (range: 1-8 years). The outcomes are summarized in Table 3.

\section{DISCUSSION}

This paper summarizes our experience in laparoscopic repair of lower midline ventral abdominal hernias with the intention of carrying out an IPOM plus repair - closure of the fascial defect with reinforcement from the peritoneal side with a composite mesh. The closure of the fascial defect has been described by various techniques - interrupted or continuous, intracorporeal or extracorporeal ${ }^{[15]}$. The extracorporeal technique consists of placing multiple stab wounds on either side of the defect to pass the suture material 
Table 3. Outcomes of follow-up

\begin{tabular}{ll}
\hline Outcomes & Data, $\boldsymbol{n}(\%)$ \\
\hline Overall morbidity & $22(7.9 \%)$ \\
Seroma & $13(4.7 \%)$ \\
Chronic pain & $5(1.8 \%)$ \\
Recurrence & $2(0.72 \%)$ \\
Mesh bulge/eventration & 1 \\
Mesh infection/rejection & Nil \\
\hline
\end{tabular}

and take interrupted stitches ${ }^{[16]}$. This may increase the risk of suture granuloma, infection or cosmetic dissatisfaction ${ }^{[17]}$. We prefer to suture the defect intracorporeally with the knots placed extracorporeally at the two ends.

Measuring the defect preoperatively in the resting supine position allows us to select an adequately sized mesh for placement, allowing a minimum of $5 \mathrm{~cm}$ overlap of the edges of defect. Literature on the subject reveals that different centers select the mesh size depending on the original defect or the closed defect ${ }^{[16]}$. However the consensus is that whichever way the defect is measured, there should be an overlap over the fascial edges of the defect of at least $5 \mathrm{~cm}$ in all directions.

Smoking was observed in almost a fifth of our patients while co-morbidities like diabetes mellitus (DM) and chronic obstructive pulmonary disease (COPD) were seen in less than $10 \%$. COPD is a relative contra-indication for laparoscopic repair due to the possibility of retention of carbon dioxide during surgery. However, all our patients were well controlled with pre-operative bronchodilators and nebulization to minimize the risks during the immediate post-operative period. Smoking, DM and COPD are also considered as risk factors for postoperative infection and recurrence ${ }^{[18-20]}$. However, other authors do not consider them as contributory factors in recurrence after umbilical hernia repair ${ }^{[21]}$. The average BMI in our series was $27 \mathrm{~kg} / \mathrm{m}^{2}$, indicating that we had a larger proportion of obese patients. Obesity is a risk factor for the occurrence of incisional hernia ${ }^{[22]}$ as well as recurrence after laparoscopic repair ${ }^{[23,24]}$. We reported operating times separately for para-umbilical hernias and incisional hernias as the fascial defect sizes would be different for both of these ventral midline hernias and hence, time taken for closure of defects would also be different. Our reported timings are in accordance with what is reported in literature $e^{[15,25]}$.

Intra-operative bowel injury occurred in five of our patients. This is in keeping with the rates reported in literature ${ }^{[6,26]}$. All the patients were being operated for incisional hernia, the bowel injured was small intestine and all the injuries occurred during sharp adhesiolysis. In 4 of the patients, the injuries were seromuscular in nature while 1 was a full thickness enterotomy. All the injuries were repaired intracorporeally with 3-0 polyglactin 910 and the surgery was completed as planned. The practice of proceeding with the IPOM repair in presence of small bowel enterotomy without gross peritoneal contamination is also reported by other authors ${ }^{[5]}$. In around $13 \%$ of our patients with incisional hernias, the fascia was thinned out or there were multiple "Swiss-cheese" type of defects where the fascial sutures would not hold. Though the defect sizes would vary, we considered the hernia to be of the size of the original scar and the mesh was selected accordingly. Hence, if even a part of the original scar was intact with multiple "Swiss cheese" defects in the remaining, the entire scar was reinforced with a mesh. In these cases, we opted for a bridging repair without closure of the fascia, a practice supported by literature ${ }^{[27,28]}$. Such bridging repairs are known to give rise to post-operative bulging of the mesh, even eventration of the mesh into the defect, as seen in 1 of our patients ${ }^{[15,29]}$.

Average hospital stay in our series was around 2 days. In general, laparoscopic repair is associated with a shorter hospital stay than open repairs of ventral hernias ${ }^{[26]}$. Seroma formation was seen in around $5 \%$ of 
our patients. The reported incidence of seroma in literature is directly proportional to the methods used to detect its presence, with the highest incidence seen when routine ultrasonography is performed for all patient ${ }^{[30]}$. The rate of this event occurring in IPOM plus is reported as $0-11.43 \%{ }^{[15]}$. Its occurrence IPOM plus as compared to standard IPOM surgery is controversial as different studies have reported IPOM plus to have better outcomes ${ }^{[27]}$, similar outcomes ${ }^{[31]}$ or worse outcomes ${ }^{[32]}$ as compared to IPOM surgery. Chronic pain, i.e., pain perceived at operative site beyond 6 months, was reported by 5 of our patients. While it has been postulated that closure of the fascia under tension may lead to higher pain perception by patients ${ }^{[15]}$, Clapp et al. ${ }^{[27]}$ reported similar rates of chronic pain after both IPOM plus and standard IPOM in their series. Two of our patients had recurrence, of which one patient had undergone an IPOM plus repair for paraumbilical hernia and the other had undergone an IPOM repair for incisional hernia. Both these patients were re-operated and an inadequately sized mesh was found to be the culprit, as after shrinkage, it had left the original defect exposed partially. In both the cases, IPOM plus repair was done laparoscopically. Literature favors IPOM plus with a lower incidence of recurrences as compared to standard IPOM surgery ${ }^{[32,33]}$.

Improvement in functional status of abdominal muscles has been reported after an IPOM Plus repair. Both Den Hartog et al. ${ }^{[34]}$ and Clapp et al. ${ }^{[27]}$ reported improved isokinetic strength of the trunk flexor muscles and better functional activity after closure of the fascial defect. Thus, IPOM plus repair is safe, feasible and with possible advantages over a standard IPOM repair as reported in literature.

\section{DECLARATIONS}

\section{Authors' contributions}

Jani K contributed solely to the paper.

\section{Data source and availability}

The data is with the author and is available for scrutiny.

\section{Financial support and sponsorship}

None.

\section{Conflicts of interest}

There are no conflicts of interest.

\section{Patient consent}

Informed consent of all patients was taken for the procedure as well as for non-indentifying inclusion in academic study.

\section{Ethics approval}

The approval of hospital ethics committee was taken for the inclusion of patients' data in the study.

\section{Copyright}

(c) The Author(s) 2018.

\section{REFERENCES}

1. Mudge M, Hughes LE. Incisional hernia: a 10-year prospective study of incidence and attitudes. Br J Surg 1985;72:70-1.

2. Lewis RT, Wiegand FM. Natural history of vertical abdominal parietal closure: prolene versus Dexon. Can J Surg 1989;32:196-200.

3. Sugerman HJ, Kellum JM Jr, Reines HD, DeMaria EJ, Newsome HH, Lowry JW. Greater risk of incisional hernia with morbidly obese than steroid-dependent patients and low recurrence with prefascial polypropylene mesh. Am J Surg 1996;171:80-4.

4. Heniford BT, Park A, Ramshaw BJ, Voeller G. Laparoscopic repair of ventral hernias nine years' experience with 850 consecutive 
hernias. Ann Surg 2003;238:391-400.

5. Carbajo MA, Martín del Olmo JC, Blanco JI, Toledano M, de la Cuesta C, Ferreras C, Vacquero C. Laparoscopic approach to incisional hernia lessons learned from 270 patients over 8 years. Surg Endosc 2003;17:118-22.

6. Sauerland S, Walgenbach M, Habermalz B, Seiler CM, Miserez M. Laparoscopic versus open surgical techniques for ventral or incisional hernia repair. Cochrane Database Syst Rev 2011;(3):CD007781.

7. Misra MC, Bansal VK, Kulkarni MP, Pawar DK. Comparison of laparoscopic and open repair of incisional and primary ventral hernia: results of a prospective randomized study. Surg Endosc 2006;12:1839-45.

8. McGreevy JM, Goodney PP, Birkmeyer CM, Finlayson SR, Laycock WS, Birkmeyer JD. A prospective study comparing the complication rates between laparoscopic and open ventral hernia repairs. Surg Endosc 2003;17:1778-80.

9. LeBlanc KA, Booth WV. Laparoscopic repair of incisional abdominal hernias using expanded polytetrafluoroethylene: preliminary findings. Surg Laparosc Endosc 1993;3:39-41.

10. Kurmann A, Visth E, Candinas D, Beldi G. Long-term follow-up of open and laparoscopic repair of large incisional hernias. World $J$ Surg 2011;35:297-301.

11. Tse GH, Stutchfield BM, Duckworth AD, de Beaux AC, Tulloh B. Pseudo-recurrence following laparoscopic ventral and incisional hernia repair. Hernia 2010;14:583-7.

12. Schoenmaeckers EJ, Wassenaar EB, Raymakers JT, Rakic S. Bulging of the mesh after laparoscopic repair of ventral and incisional hernias. JSLS 2010;14:541-6.

13. Palanivelu C, Jani KV, Senthilnathan P, Parthasarathi R, Madhankumar MV, Malladi VK. Laparoscopic sutured closure with mesh reinforcement of incisional hernias. Hernia 2007;11:223-8.

14. Bittner R, Bingener-Casey J, Dietz U, Fabian M, Ferzli GS, Fortelny RH, Köckerling F, Kukleta J, Leblanc K, Lomanto D, Misra MC, Bansal VK, Morales-Conde S, Ramshaw B, Reinpold W, Rim S, Rohr M, Schrittwieser R, Simon T, Smietanski M, Stechemesser B, Timoney M, Chowbey P; International Endohernia Society (IEHS). Guidelines for laparoscopic treatment of ventral and incisional abdominal wall hernias (International Endohernia Society (IEHS)-part 1. Surg Endosc 2014;28:2-29.

15. Suwa K, Okamoto T, Yanaga K. Closure versus non-closure of fascial defects in laparoscopic ventral and incisional hernia repairs: a review of the literature. Surg Today 2016;46:764-73.

16. Franklin ME, Gonzalez JJ, Glass JL, Manjarrez A. Laparoscopic ventral and incisional hernia repair: 11-year experience. Hernia 2004;8:23-7.

17. Nguyen DH, Nguyen MT, Askenasy EP, Kao LS, Liang MK. Primary fascial closure with laparoscopic ventral hernia repair: systematic review. World J Surg 2014;38:3097-104.

18. Usher FC, Ochsner J, Tuttle LL Jr. Use of marlex mesh in the repair of incisional hernias. Am Surg 1958;24:969-74.

19. Clave A, Yahi H, Hammou JC, Montanari S, Gounon P, Clave H. Polypropylene as a reinforcement in pelvic surgery is not inert: comparative analysis of 100 explants. Int Urogynecol J 2010;21:261-70.

20. Klinge U, Klosterhalfen B, Muller M, Schumpelick V. Foreign body reaction to meshes used for the repair of abdominal wall hernias. Eur J Surg 1999;165:665-73.

21. Asolati M, Huerta S, Sarosi G, Harmon R, Bell C, Anthony T. Predictors of recurrence in veteran patients with umbilical hernia: single center experience. Am J Surg 2006;192:627-30.

22. LeBlanc KA, Booth WV. Laparoscopic repair of incisional abdominal hernias using expanded polytetrafluoroethylene: preliminary findings. Surg Laparosc Endosc 1993;3:39-41.

23. Weiland DE, Bay RC, Del Sordi S. Choosing the best abdominal closure by meta-analysis. Am J Surg 1998;176:666-70.

24. Moreno-Egea A, Carrillo-Alcaraz A, Soria-Aledo V. Randomized clinical trial of laparoscopic hernia repair comparing titanium-coated lightweight mesh and medium-weight composite mesh. Surg Endosc 2013;27:231-9.

25. Hajibandeh S, Hajibandeh S, Sreh A, Khan A, Subar D, Jones L. Laparoscopic versus open umbilical or paraumbilical hernia repair: a systematic review and meta-analysis. Hernia 2017;21:905-16.

26. Bittner R, Bingener-Casey J, Dietz U, Fabian M, Ferzli G, Fortelny R, Köckerling F, Kukleta J, LeBlanc K, Lomanto D, Misra M, Morales-Conde S, Ramshaw B, Reinpold W, Rim S, Rohr M, Schrittwieser R, Simon T, Smietanski M, Stechemesser B, Timoney M, Chowbey P. Guidelines for laparoscopic treatment of ventral and incisional abdominal wall hernias (International Endohernia Society [IEHS])-Part III. Surg Endosc 2014;28:380-404.

27. Clapp ML, Hicks SC, Awad SS, Liang MK. Transcutaneous closure of central defects (TCCD) in laparoscopic ventral hernia repairs (LVHR). World J Surg 2012;37:42-51.

28. Liang MK, Subramanian A, Awad S. Laparoscopic transcutaneous closure of central defects in laparoscopic incisional hernia repair. Surg Laparosc Endosc Percutan Tech 2012;22:e66-70.

29. Carter SA, Hicks SC, Brahmbhatt R, Liang MK. Recurrence and pseudorecurrence after laparoscopic ventral hernia repair: predictors and patient-focused outcomes. Am Surg 2014;80:138-48.

30. Bittner R, Bingener-Casey J, Dietz U, Fabian M, Ferzli GS, Fortelny RH, Köckerling F, Kukleta J, LeBlanc K, Lomanto D, Misra MC, Morales-Conde S, Ramshaw B, Reinpold W, Rim S, Rohr M, Schrittwieser R, Simon T, Smietanski M, Stechemesser B, Timoney M, Chowbey P. Guidelines for laparoscopic treatment of ventral and incisional abdominal wall hernias (International Endohernia Society [IEHS])-Part 2. Surg Endosc 2014;28:353-79.

31. Lambrecht JR, Vaktskjold A, Trondsen E, Øyen OM, Reiersten O. Laparoscopic ventral hernia repair: outcomes in primary versus 
incisional hernias: no effect of defect closure. Hernia 2015;19:479-86.

32. Zeichen MS, Lujan HJ, Mata WN, Maciel VH, Lee D, Jorge I, Plasencia G, Gomez E, Hernandez AM. Closure versus nonclosure of hernia defect during laparoscopic ventral hernia repair with mesh. Hernia 2013;17:589-96.

33. Banerjee A, Beck C, Narula VK, Linn J, Noria S, Zagol B, Mikami DJ. Laparoscopic ventral hernia repair: does primary repair in addition to placement of mesh decrease recurrence? Surg Endosc 2012;26:1264-8.

34. Den Hartog D, Eker HH, Tuinebreijer WE, Kleinrensink GJ, Stam HJ, Lange JF. Isokinetic strength of the trunk flexor muscles after surgical repair for incisional hernia. Hernia 2010;14:243-7. 